\title{
Protective effects of extendin-4 on hypoxia/reoxygenation-induced injury in $\mathrm{H} 9 \mathrm{c} 2$ cells
}

\author{
KAI LU ${ }^{1}$, GUANGLEI CHANG ${ }^{1}$, LIN YE ${ }^{1}$, PENG ZHANG $^{1}$, YONG LI $^{2}$ and DONGYING ZHANG ${ }^{1}$ \\ ${ }^{1}$ Department of Cardiology, The First Affiliated Hospital of Chongqing Medical University, Chongqing 400016, P.R. China; \\ ${ }^{2}$ Center for Perinatal Biology, Division of Pharmacology, Department of Basic Sciences, \\ Loma Linda University School of Medicine, Loma Linda, CA 92350, USA
}

Received June 12, 2014; Accepted February 24, 2015

DOI: $10.3892 / \mathrm{mmr} .2015 .3682$

\begin{abstract}
Glucagon-like peptide-1 (GLP-1) analogues are likely to exert cardioprotective effects via balancing the energy metabolism in cardiomyocytes following ischemic or hypoxic insults. The present study aimed to explore the protective effects and mechanism of exendin-4, a GLP-1 analogue, on cardiomyocyte glucose uptake using an in vitro model of hypoxia/reoxygenation $(\mathrm{H} / \mathrm{R})$ of $\mathrm{H} 9 \mathrm{c} 2$ cardiomyocyte cells. Pre-treatment with exendin-4 (200 nM) prior to H/R increased the cell viability, decreased cell apoptosis, enhanced cardiomyocyte glucose uptake and increased the production of adenosine triphosphate. Exendin-4 also decreased the levels of lactate dehydrogenase and creatine kinase-MB in the culture medium. Furthermore, the activity of carnitine palmitoyltransferase- 1 in the H9c2 cells was decreased, while the activity of phosphofructokinase-1 was increased following exendin-4 treatment. Moreover, pre-treatment with exendin-4 increased the expression of p38 mitogen-activated protein kinase (p38MAPK) $\gamma$ and translocation of glucose transporter-1 in H9c2 cells subjected to H/R. However, these effects were attenuated by the p38MAPK inhibitors BIRB796 and SB203580. The results suggested that exendin-4 exerted significant cardioprotective effects against $\mathrm{H} / \mathrm{R}$-induced cell injury and restored the metabolic imbalance of cardiomyocytes by activating the p38MAPK signaling pathway in the H9c2 cell model. Importantly, p38MAPK $\gamma$, one subunit of p38MAPK, may have the most important function in this process. The results of the present study may be helpful in the development of novel drugs to treat patients with coronary heart disease.
\end{abstract}

Correspondence to: Professor Dongying Zhang, Department of Cardiology, The First Affiliated Hospital of Chongqing Medical University, 1 Yixueyuan Road, Chongqing 400016, P.R. China E-mail: zdy.chris@gmail.com

Key words: glucagon-like peptide-1, exendin-4, glucose uptake, hypoxia/reoxygenation

\section{Introduction}

When cardiomyocytes suffer from ischemic or hypoxic insults, the metabolic balance between glucose and fatty acid shifts to fatty acid oxidation, which aggravates the oxygen deficiency, as fatty acid consumes $10 \%$ more oxygen than glucose when an equal amount of adenosine triphosphate (ATP) is produced. Furthermore, increased fatty acid oxidation has been reported to induce mitochondrial uncoupling and increase oxidative stress $(1,2)$. Normalizing metabolic imbalances, which are underlying causes of metabolic disorders, has been one of the targets for the treatment of ischemic heart diseases (3).

Glucagon-like peptide-1 (GLP-1), an incretion hormone, has been confirmed to potently promote insulin secretion and downregulate glucose levels, which gives it a high potential to be used for the treatment of diabetes patients (4-7). However, its half life time is too short for it to be used in clinic (8). Therefore, analogues with significantly longer half-lives, such as exendine-4, have been developed and used in the clinic (9). Over the last decade, a growing body of evidence has demonstrated that GLP-1 and its analogues can exert protective effects on cardiomyocytes with ischemic or hypoxic damage (10-13); however, the exact mechanism is still elusive. Studies have reported that GLP-1 and its analogues increased the glucose uptake and helped to preserve the cardiac function in animal experiments and clinical trials $(13,14)$. However, whether exendine- 4 can contribute to restore the metabolic balance between glucose oxygen and fatty acid oxidation and therefore ameliorate the energy imbalance of hypoxia-induced cardiomyocytes has not been fully elucidated.

The aim of the present study was to determine whether exendin-4 is capable of reducing hypoxia/reoxygenation $(\mathrm{H} / \mathrm{R})$-induced injury by normalizing the energy imbalance in cardiomyocytes. For this, a model of hypoxia/reoxygenation $(\mathrm{H} / \mathrm{R})$-induced injury in $\mathrm{H} 9 \mathrm{c} 2$ cardiomyocyte cells was established to assess the effects of exendin- 4 on glucose uptake. The possible mechanism involved in this process was also investigated by assessing the activation of the p38 mitogen-activated protein kinase (MAPK) signaling pathway.

\section{Materials and methods}

Cell culture and hypoxia/reoxygenation treatment. $\mathrm{H} 9 \mathrm{c} 2$ cells (Chinese Academy of Medical Sciences, Shanghai, China) 
were cultured in Dulbecco's modified Eagle's medium: Nutrient Mixture F-12 (DMEM/F12; Thermo Fisher Scientific, Waltham, MA, USA) supplemented with $10 \%$ fetal bovine serum (FBS; Invitrogen Life Technologies, Carlsbad, CA, USA), in $50-\mathrm{cm}^{2}$ flasks in a humidified atmosphere of $5 \%$ $\mathrm{CO}_{2}$ at $37^{\circ} \mathrm{C}$. The hypoxia/reoxygenation $(\mathrm{H} / \mathrm{R})$ model was established according to the methods described in previous studies with certain modifications (15). Briefly, when cells were cultured to $80 \%$ confluence in appropriate culture, they were subjected to hypoxia using DMEM/F12 without FBS and glucose in a hypoxia chamber (Forma 370; Thermo Fisher Scientifiic, Waltham, MA, USA) saturated with a gas mixture $\left(95 \% \mathrm{~N}_{2}\right.$ and $\left.5 \% \mathrm{CO}_{2}\right)$ at $37^{\circ} \mathrm{C}$. Following hypoxia treatment, the culture medium was replaced with fresh normal medium and the plate was placed in the humidified atmosphere of 5\% $\mathrm{CO}_{2}$ to receive reoxygenation treatment. Different treatment times of hypoxia and reoxygenation were used to determine the optimal time for establishing the H/R model. Exendine-4 (Eli Lilly, Indianapolis, IN, USA), a GLP-1 analogue, was added to the culture medium for $30 \mathrm{~min}$ before they were subjected to hypoxia. In certain cases, inhibitors of p38MAPK, BIRB796 $(1 \mu \mathrm{M})$ and SB203580 $(5 \mu \mathrm{M})$ (Santa Cruz Biotechnology Inc., Dallas, TX, USA), were added to the culture medium $10 \mathrm{~min}$ prior to treatment with exendine- 4 .

Cell counting kit (CCK)-8 assay. Cell viability was assessed using the CCK-8 (Beyotime Institute of Biotechnology, Haimen, China) as described previously with certain modifications (16). The H9c2 cells $\left(1 \times 10^{4}\right)$ were seeded in 96-well microplates. Folowing H/R treatment $(4 / 2,6 / 3,12 / 4,14 / 5,16 / 6$ and $22 / 10 \mathrm{~h})$ with or without exendine- $4(0,50,100,200$ and $300 \mathrm{nM}$, respectively), cells were cultured in fresh medium and $10 \mu$ l CCK- 8 solution. The plates were then incubated in the humidified atmosphere of $5 \% \mathrm{CO}_{2}$ at $37^{\circ} \mathrm{C}$ for $2 \mathrm{~h}$. Finally, the optical density (OD) values at $470 \mathrm{~nm}$ were measured using a microplate reader (Multiskan MK33; Thermolab systems, Helsinki, Finland).

Measurement of myocardial glucose uptake. Myocardial glucose uptake was measured as the levels of intracellular 2-(N-(7-nitrobenz-2-oxa-1,3-diazol-4-yl)amino)-2-deoxyglucose (2-NBDG). 2-NBDG is a fluorescent labeled glucose analogue, which can be transported into the cytoplasm from the culture medium but cannot be metabolized further (17). Following incubation for $30 \mathrm{~min}$, cells were rinsed with phosphate-buffered saline (PBS) and the fluorescent density was measured by a microplate reader (721D; Pudong Shanghai Physical Optical Instrument Factory, Shanghai, China) at an excitation wavelength (Ex.) of $488 \mathrm{~nm} / \mathrm{and}$ an emission wavelength (Em.) of $520 \mathrm{~nm}$. The total fluorescent density of every well was adjusted by the OD values of cell viability from the CCK- 8 cell counting kit assay, which was performed as soon as the measurement of the fluorescent density was finished. The actual intracellular glucose levels were defined as the ratio of fluorescent density (arbitrary unit, a.u.) to the OD values of cell viability.

Colorimetry. The levels of lactate dehydrogenase (LDH) in the culture medium, as well as the activity of phosphofructokinase-1 (PFK-1) and carnitine palmitoyltransferase-1 (CPT-1) in the H9c2 cells were determined by colorimetry. The experiment was performed using commercially available kits according to the manufacturer's instructions. The LDH Activty Colorimetric assay was purchased from Jiancheng Bioengineering Institute (Nanjing, China). The PFK-1 and CPT-1 Activty Colorimetric assays were purchased from Sigma-Aldrich (St. Louis, MO, USA). Briefly, culture medium was separated by centrifugation at $1,600 \mathrm{xg}$ for $10 \mathrm{~min}$ at $4^{\circ} \mathrm{C}$ and then used for the measurement of the LDH levels. The H9c2 cells were collected and lysed with cell lysis buffer (Beyotime Institute of Biotechnology, Haimen, China). The cell lysates were then centrifuged at $1,600 \mathrm{xg}$ for $10 \mathrm{~min}$ at $4^{\circ} \mathrm{C}$ and the supernatants of were collected for the detection of PFK-1 and CPT-1 activity. Following incubation with the reagents included in the kits, the absorbance values at 340 and $420 \mathrm{~nm}$ were measured continuously using a spectrophotometer (Multiskan MK33, Thermolab systems, Helsinki, Finland). The LDH levels was expressed as U/l. The activity of PFK-1 and CPT-1 was defined as the fold-change in enzyme activity relative to that in the control group. The protein concentration was determined using the bicinchoninic acid (BCA) protein assay (Beyotime Institute of Biotechnology) (18).

ELISA assays. The levels of creatine kinase-MB (CK-MB) in the culture medium were measured using a CK-MB ELISA assay kit (R\&D Systems, Minneapolis, MN, USA) according to the manufacturer's instructions. Following the indicated treatments as mentioned above, the culture medium were collected and centrifuged at $1,600 \mathrm{xg}$ for $10 \mathrm{~min}$ at $4^{\circ} \mathrm{C}$. The supernatants were collected for the detection of CK-MB. The supernatants were then incubated with the reagents included in the kits. Finally, the absorbance values were measured using a microplate reader (Multiskan MK33; Thermolab systems, Helsinki, Finland) at $450 \mathrm{~nm}$. The CK-MB levels were expressed as U/1.

Flow cytometry. Cell apoptosis was examined using flow cytometry. H9c2 cells $\left(2 \times 10^{4} / 100 \mu \mathrm{l}\right)$ were seeded in six-well plates for $72 \mathrm{~h}$. After the indicated treatments mentioned above, cells were collected, washed with cold PBS and resuspended at a density of $1 \times 10^{6} / \mathrm{ml}$. Cells $(500 \mu \mathrm{l})$ were mixed with $5 \mu \mathrm{l}$ Annexin V-fluorescein isothiocyanate (Beyotime Institute of Biotechnology) and $10 \mu \mathrm{l}$ propidium iodide (PI, $20 \mathrm{mg} / \mathrm{ml}$; Beyotime Institute of Biotechnology) and incubated for $20 \mathrm{~min}$ in the dark at room temperature. Flow cytometric analysis (Ex. $488 \mathrm{~nm} / \mathrm{Em} .530 \mathrm{~nm}$ ) was performed with a FACSCalibur cell sorter (BD Biosciences, Franklin Lakes, NJ, USA). Flow cytometric data were analyzed using CellQuest ${ }^{\mathrm{TM}}$ version 4.5 software (BD Biosciences).

ATP measurement. Cellular ATP content was measured using the ATP bioluminescent assay kit (Beyotime Institute of Biotechnology) according to the manufacturer's instructions. For each experiment, cells were briefly washed two times with ice-cold PBS, resuspended in $100 \mu 1$ Tris-EDTA buffer $(100 \mathrm{mM}$ Tris- $\mathrm{HCl}$ and $4 \mathrm{mM}$ EDTA, $\mathrm{pH}$ 7.55; Beyotime Institute of Biotechnology) and then incubated for $3 \mathrm{~min}$ at $100^{\circ} \mathrm{C}$. Following centrifugation at $10,000 \mathrm{xg}$ for $2 \mathrm{~min}$, supernatants were extracted and $10 \mu \mathrm{l}$ of them plus $40 \mu \mathrm{l}$ ATP assay buffer was added into the wells of a microplate, which had each been filled with $50 \mu \mathrm{l}$ ATP reaction mix (ATP assay buffer, $48.5 \mu \mathrm{l}$; ATP probe, $0.2 \mu 1$; ATP converter, $2.0 \mu 1$; and Development mix, 

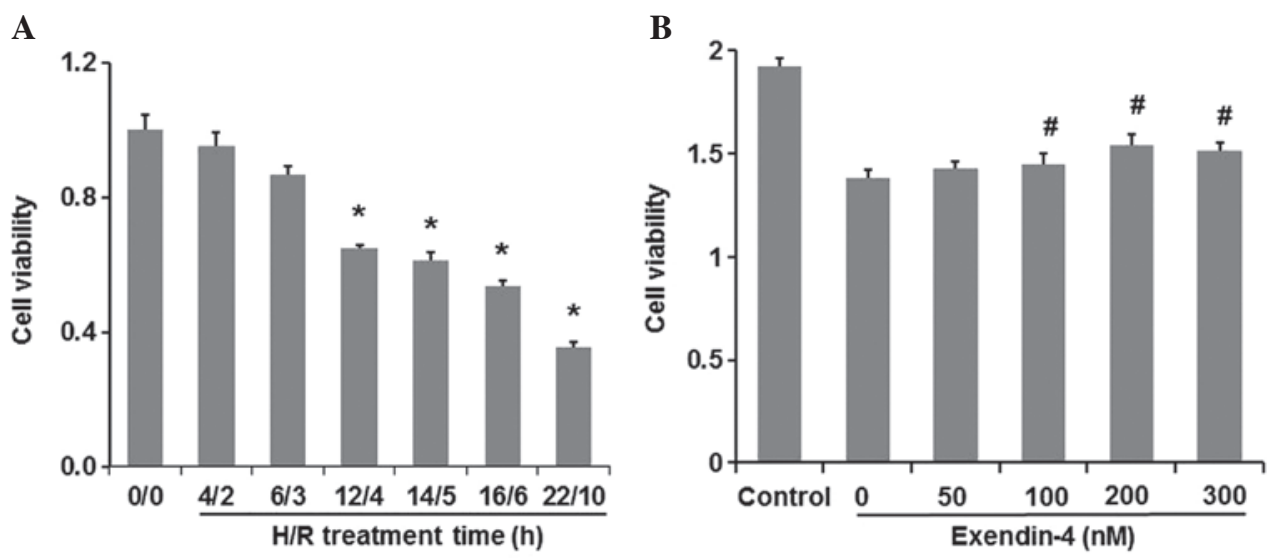

Figure 1. Effects of H/R on cell viability of H9c2 cells and the protective effects of exendin-4 on H/R-induced injury. (A) H9c2 cells were exposed to H/R conditions for different time periods $(4 / 2,6 / 3,12 / 4,14 / 5,16 / 6$ and 22/10 h). (B) H9c2 cells were pre-treated with exendin-4 (0, 50, 100, 200 and 300 nM, respectively) for $30 \mathrm{~min}$ prior to treatment of $12 \mathrm{~h}$ hypoxia and followed by $4 \mathrm{~h}$ reoxygenation. After the H/R treatment, cell viability was assessed using cell counting kit-8. Values are expressed as the percentage of the control and presented as the mean \pm standard deviation $(\mathrm{n}=6)$. ${ }^{*} \mathrm{P}<0.05$ versus control group $(0 / 0)$; ${ }^{\#} \mathrm{P}<0.05$ versus the 0 group. $\mathrm{H} / \mathrm{R}$, hypoxia/reoxygenation.

A

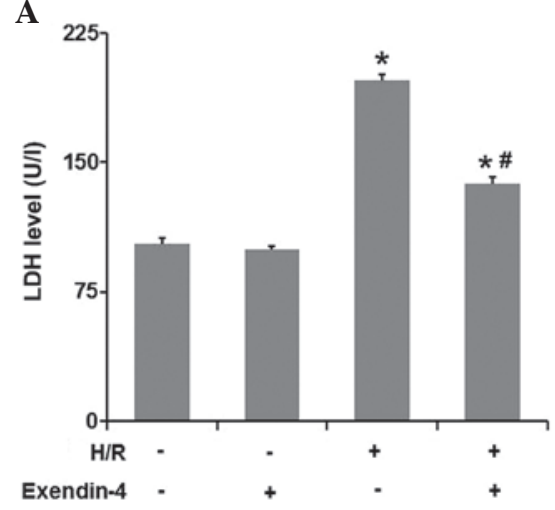

B

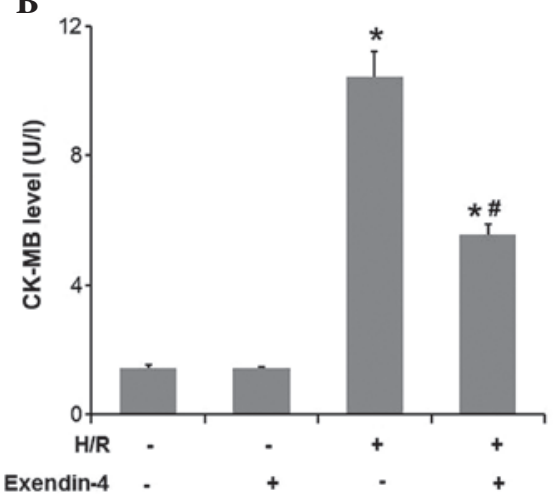

Figure 2. Effects of exendin-4 on LDH and CK-MB levels in the culture medium. H9c2 cells were pre-treated with exendin-4 (200 nM) for 30 min prior to /R (12/4 h). (A) Effect of exendin-4 on the LDH levels in the culture medium. (B) Effect of exendin-4 on the CK-MB levels in the culture medium. LDH levels and CK-MB levels in the culture medium were detected by colorimetry and ELISA assay, respectively, and were expressed as U/1. Values are expressed as the mean \pm standard deviation $(n=6)$. ${ }^{*} \mathrm{P}<0.05$ vs. control group; ${ }^{\sharp} \mathrm{P}<0.05$ vs. H/R group. LDH, lactate dehydrogenase; H/R, hypoxia/reoxygenation; $\mathrm{CK}-\mathrm{MB}$, creatine kinase-MB.

$2.0 \mu \mathrm{l})$. The microplate was covered with aluminium foil and incubated at $37^{\circ} \mathrm{C}$ for 30 min prior to measuring the OD at Ex. $535 \mathrm{~nm} / \mathrm{Em} .587 \mathrm{~nm}$ using a microplate reader (721D; Pudong Shanghai Physical Optical Instrument Factory).

Western blot analysis. Membrane proteins of $\mathrm{H} 9 \mathrm{c} 2$ cells were extracted from cell lysates using a membrane protein extraction kit (Beyotime Institute of Biotechnology, Haimen, China). The protein concentration was determined using the BCA assay (Beyotime Institute of Biotechnology). Protein samples (40 or $20 \mu \mathrm{g}$ ) were mixed with $2 \mathrm{X}$ SDS sample loading buffer (Beyotime Institute of Biotechnology) and then separated on a $12 \%$ polyacrylamide gel and blotted on a nitrocellulose membrane (Beyotime Institute of Biotechnology). Blots were blocked with 5\% skimmed milk, followed by incubation with antibodies specific to p38MAPK $\alpha$ (1:100; cat. no. sc-398305; Santa Cruz Biotechnology Inc.), p38MAPK $\gamma$ (1:100; cat. no. sc-366013; Santa Cruz Biotechnology Inc.), GLUT-1 (1:100; cat. no. ab652; Abcam Trading Company Ltd., Shanghai, China), GLUT-4 (1:100; cat. no. 7796-3; Epitomics
Biotechnology Inc., Burlingame, CA, USA) or $\beta$-actin $(1: 1,000$; cat. no. sc-130656; Santa Cruz Biotechnology Inc,). Blots were then incubated at room temperature for $30 \mathrm{~min}$ with secondary antibody (1:1,000; cat. no. zm0441; Zhongshan Goldenbridge Biotechnology Corporation) and an enhanced chemiluminescence detection system (Bio-Rad, Hercules, CA, USA) was used for visualization. The grey value was measured using Quantity One version 4.5 software (Bio-Rad).

Statistical analysis. SPSS 17.0 software (SPSS, Inc., Chicago, IL, USA) was used for statistical analysis. Values are expressed as the mean \pm standard deviation. Differences between groups were determined by one-way analysis of variance followed Dunnett's post-hoc test and $\mathrm{P}<0.05$ was considered to indicate a statistically significant difference between values.

\section{Results}

Exentin-4 increases the viability of $H 9 \mathrm{c} 2$ cells subjected to $H / R$. Following H/R for various times (4/2, 6/3, 12/4, 14/5, 16/6 
A

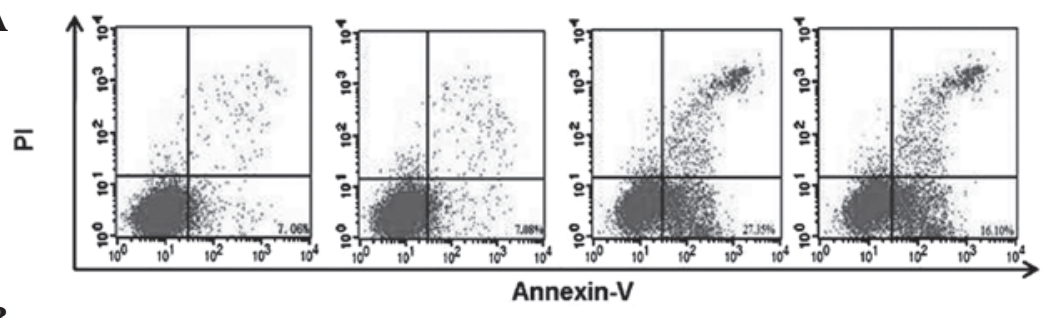

B

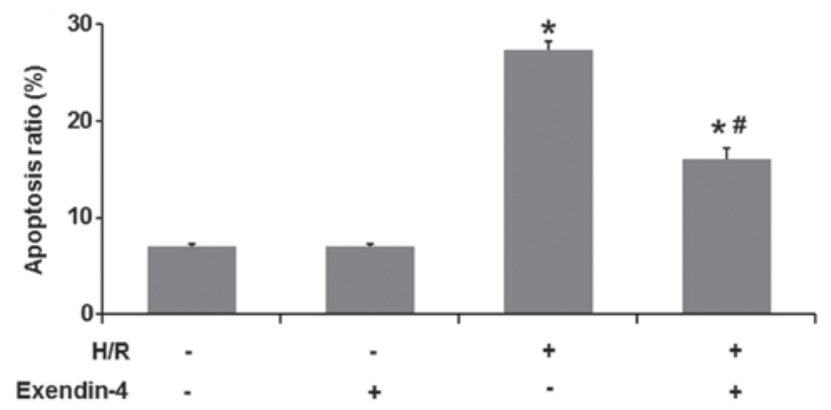

Figure 3. Effects of exendin-4 on apoptosis in H/R-treated H9c2 cells. H9c2 cells were pre-treated with exendin-4 (200nM) for $30 \mathrm{~min}$ prior to H/R (12/4 h). Apoptosis of H9c2 cells was measured by flow cytometry. (A) Representative dot plots of flow cytometric analysis of apoptotic cells using PI/Annexin V double staining. (B) Quantified results of flow cytometric analysis. The apoptotic rate was the percentage of Annexin V-positive and PI-negative cells among the cells analyzed. Values are expressed as the mean \pm standard deviation $(n=3)$. ${ }^{*} \mathrm{P}<0.05$ vs. control group; ${ }^{*} \mathrm{P}<0.05$ vs. H/R group. PI, propidium iodide; H/R, hypoxia/reoxygenation.

and 22/10 h), H9c2 cell viability was assessed using a CCK-8 kit. As shown in Fig. 1A, cell viability decreased in an $H / R$ time-dependent manner. Cell viability after $4 / 2 \mathrm{~h}$ and $6 / 3 \mathrm{~h}$ $\mathrm{H} / \mathrm{R}$ decreased to 95.21 and $86.90 \%$, respectively, compared with that in the control group $(\mathrm{P}<0.05)$, while $12 / 4,14 / 5,16 / 6$ and $22 / 10 \mathrm{~h} \mathrm{H} / \mathrm{R}$ further decreased the cell viability to 64.99 , $61.44,53.65$ and $35.52 \%$ of the control, respectively $(\mathrm{P}<0.05)$. As $12 / 4 \mathrm{~h}$ was the shortest $\mathrm{H} / \mathrm{R}$ time that caused a significant difference in cell viability $(\mathrm{P}<0.05)$, these conditions were then selected to investigate the potential effects of exentin-4 on cardiomyocyte protection.

H9c2 cells were pre-treated with exentin-4 $(0,50,100$, 200 and $300 \mathrm{nM}$, respectively) for $30 \mathrm{~min}$ prior to H/R treatment $(12 / 4$ h). Fig. 1B shows that treatment with exendin-4 increased $\mathrm{H} 9 \mathrm{c} 2$ cell viability even at the lowest concentration of $50 \mathrm{nM}$. The percentage of cells surviving the H/R insult was increased by exendin- 4 in a dose-dependent manner between 0 and $200 \mathrm{nM}$, and the cell viability reached a peak in the presence of $200 \mathrm{nM}$ exendin-4. When the concentration of exendin- 4 was further increased to $300 \mathrm{nM}$, the percentage of surviving cells did not increase correspondingly, but was slightly decreased; however, this change was not significant. These results strongly suggested that exendin- 4 exerted a protective effect against H/R injury of H9c2 cardiomyocyte cells. Exendin- 4 achieved the best efficiency to protect cell viability at a concentration of $200 \mathrm{nM}$. Therefore, the concentration of $200 \mathrm{nM}$ was selected for the treatment of $\mathrm{H} 9 \mathrm{c} 2$ cells in the following experiment.

Exentin- 4 reduces $L D H$ and $C K-M B$ release in $H 9 c 2$ cells subjected to $H / R$. As LDH and CK-MB release are two acknowledged markers for cardiomyocyte injury, these proteins were examined in the culture medium (Fig. 2A and B). LDH and CK-MB release significantly increased in the $\mathrm{H} / \mathrm{R}$ group compared to that in the control

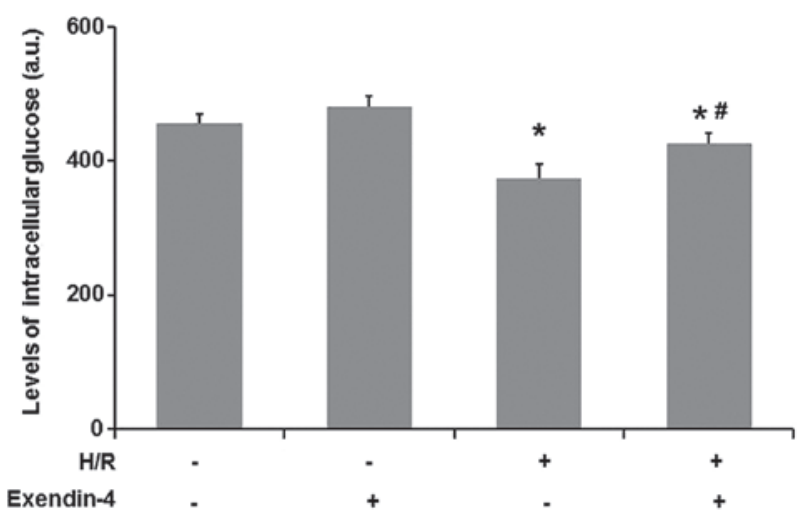

Figure 4. Effects of exendin-4 on intracellular glucose levels in H/R-treated $\mathrm{H} 9 \mathrm{c} 2$ cells. H9c2 cells were pre-treated with exendin-4 (200 nM) for $30 \mathrm{~min}$ prior to $\mathrm{H} / \mathrm{R}(12 / 4 \mathrm{~h})$. Intracellular glucose levels were measured using 2-( $N$-(7-nitrobenz-2-oxa-1,3-diazol-4-yl)amino)-2-deoxyglucose, a fluorescence-labeled glucose analogue. Values are expressed as the mean \pm standard deviation ( $\mathrm{n}=6$ ). ${ }^{*} \mathrm{P}<0.05$ vs. control group; ${ }^{*} \mathrm{P}<0.05$ vs. $\mathrm{H} / \mathrm{R}$ group. $\mathrm{H} / \mathrm{R}$, hypoxia/reoxygenation.

group $(\mathrm{P}<0.05)$, while pre-treatment with $200 \mathrm{nM}$ exendin-4 significantly decreased LDH and CK-MB release induced by $H / R(P<0.05)$. These results strongly suggested that exendin- 4 exerted a protective effect against the $H / R$ injury of $\mathrm{H} 9 \mathrm{c} 2$ cardiomyocyte cells.

Exendin-4 attenuates H/R-induced apoptosis of $H 9 c 2$ cells. The present study investigated the effect of exendin- 4 on the H/R-induced apoptosis in cultured $\mathrm{H} 9 \mathrm{c} 2$ cells using flow cytometry (Fig. 3A and B). The results of the flow cytometric analysis suggested that the number of apoptotic cells in the $\mathrm{H} / \mathrm{R}$ treatment group was higher than that in the control group $(\mathrm{P}<0.05)$. Pre-treatment with $200 \mathrm{nM}$ exendin- 4 decreased the amount of apoptotic cells in comparison to that in the H/R 
A

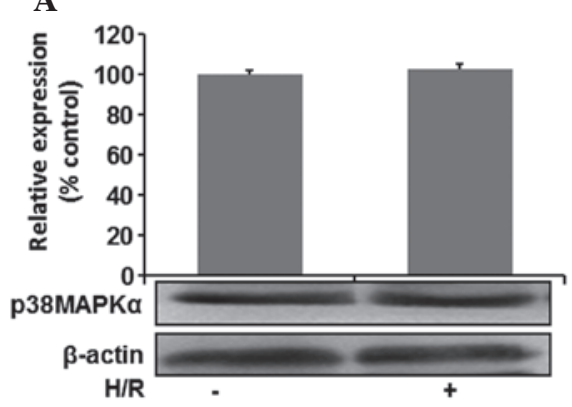

C

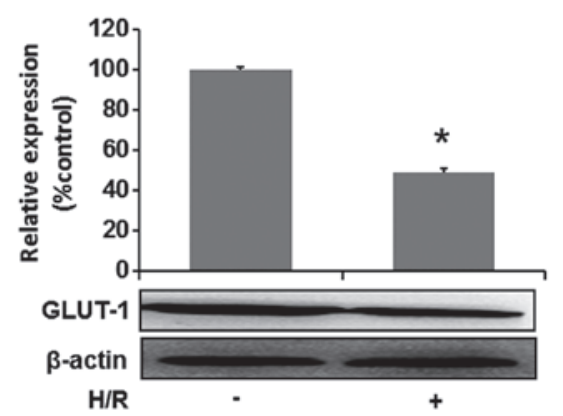

B

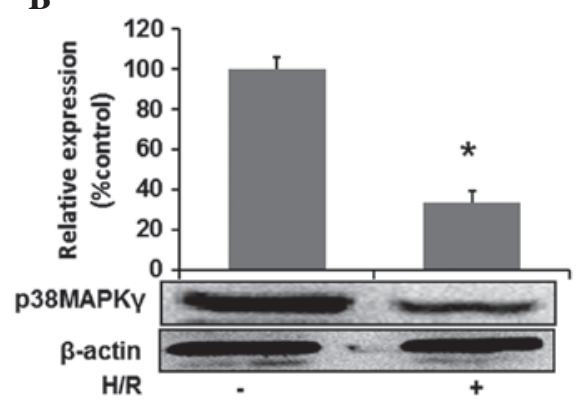

D

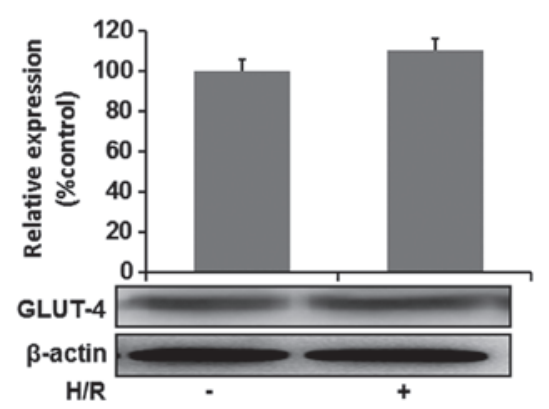

Figure 5. Effects of H/R on p38MAPK $\alpha$ and $\gamma$ expression as well as GLUT-1 and -4 translocation in H9c2 cells. H9c2 cells were subjected to hypoxia/reoxygenation $(12 / 4 \mathrm{~h})$ prior to protein extraction. p38MAPK $\alpha$ and $\gamma$ expression and GLUT-1 and -4 translocation were measured by western blot analysis. GLUT translocation was evaluated by analyzing the GLUT expression on the cytomembrane after H/R treatment. (A) p38MAPK $\alpha$ levels, (B) p38MAPK $\gamma$ levels, (C) GLUT-1 levels and (D) GLUT-4 levels were determined by western blot analysis. Values are expressed as the mean \pm standard deviation ( $\mathrm{n}=4$ ). " $\mathrm{P}<0.05$ vs. H/R group. H/R, hypoxia/reoxygenation; MAPK, mitogen-activated protein kinase; GLUT, glucose transporter.

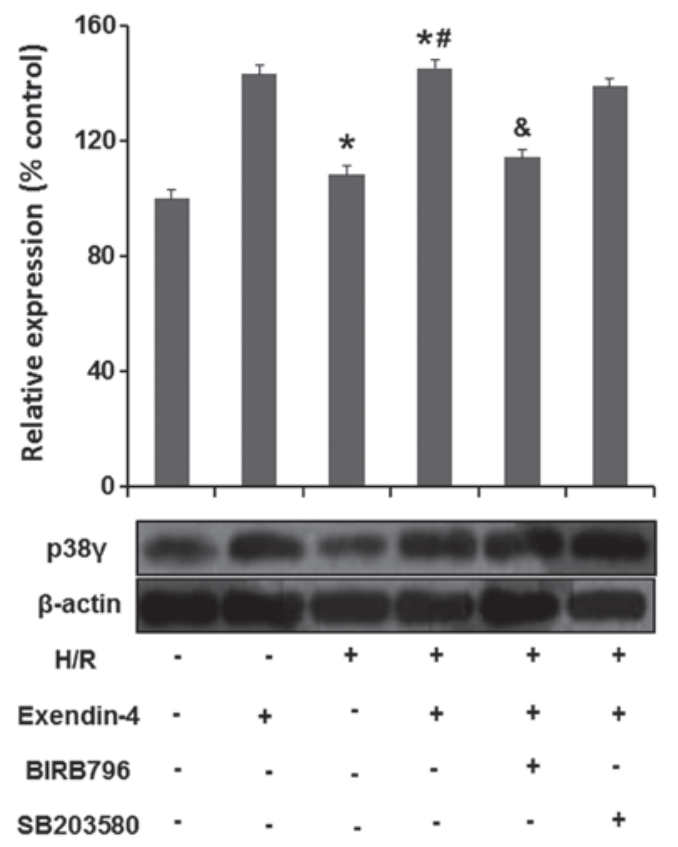

Figure 6. Effects of exendin-4 on p38MAPK $\gamma$ expression in H/R-treated H9c2 cells. H9c2 cells were pre-treated with exendin-4 (200 nM) for $30 \mathrm{~min}$ prior to $\mathrm{H} / \mathrm{R}(12 / 4 \mathrm{~h})$. Two inhibitors of p38MAPK, BIRB796 $(1 \mu \mathrm{M})$ and SB203580 $(5 \mu \mathrm{M})$, were added to the culture medium and incubated for $10 \mathrm{~min}$ before the cells were treated with exendine-4. p38MAPK $\gamma$ expression was measured by western blot analysis. Values are expressed as the mean \pm standard deviation. ${ }^{*} \mathrm{P}<0.05$ vs. control group; ${ }^{\#} \mathrm{P}<0.05$ vs. $\mathrm{H} / \mathrm{R}$ group; ${ }^{\&} \mathrm{P}<0.05$ vs. exendin- $4+$ HR group. H/R, hypoxia/reoxygenation; MAPK, mitogen-activated protein kinase.

group $(\mathrm{P}<0.05)$, which suggested that exendin-4 attenuated $\mathrm{H} / \mathrm{R}$-induced apoptosis of $\mathrm{H} 9 \mathrm{c} 2$ cells.

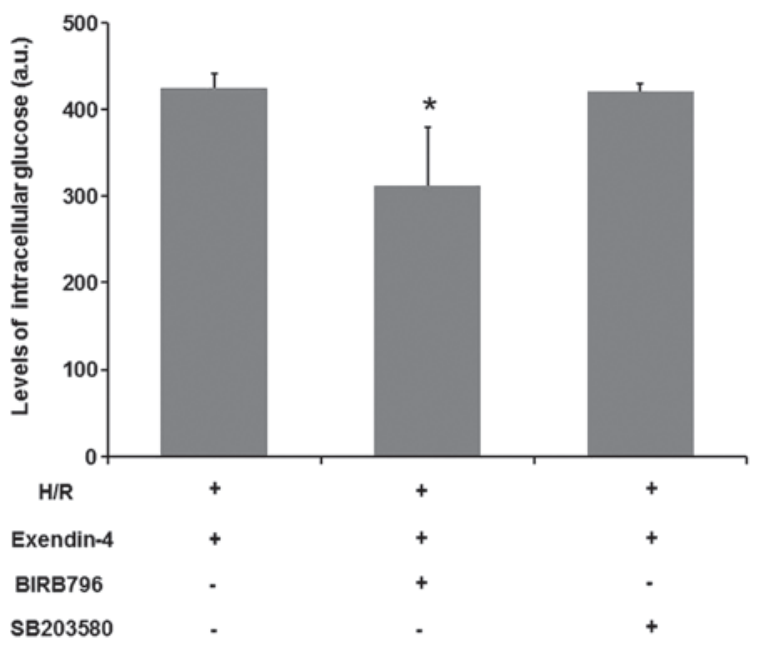

Figure 7 Effects of mitogen-activated protein kinase inhibitors BIRB796 and SB203580 on intracellular glucose in exendin-4-treated H9c2 cells. $\mathrm{H} 9 \mathrm{c} 2$ cells were pre-treated with exendin-4 $(200 \mathrm{nM})$ for $30 \mathrm{~min}$ prior to $\mathrm{H} / \mathrm{R}(12 / 4 \mathrm{~h})$. BIRB796 $(1 \mu \mathrm{M})$ and SB203580 $(5 \mu \mathrm{M})$ were added to the culture medium and incubated for $10 \mathrm{~min}$ before the cells were treated with exendine-4. Intracellular glucose was measured using 2-( $N$-(7-nitrobenz-2-oxa-1,3-diazol-4-yl)amino)-2-deoxyglucose, a fluorescence labeled glucose analogue. Values are expressed as the mean \pm standard deviation $(\mathrm{n}=6)$. ${ }^{*} \mathrm{P}<0.05$ vs. $\mathrm{H} / \mathrm{R}+$ exendine- 4 group. $\mathrm{H} / \mathrm{R}$, hypoxia/reoxygenation.

Exendin-4 enhances glucose uptake in H/R-injured $H 9 c 2$ cells. An increase of glucose uptake in cardiomyocytes is beneficial in protecting the heart against ischemic injury (19). To explore the possible mechanisms involved in the protection of cardiomyocytes by exendin-4, intracellular glucose levels were determined. As Fig. 4 shows, the 


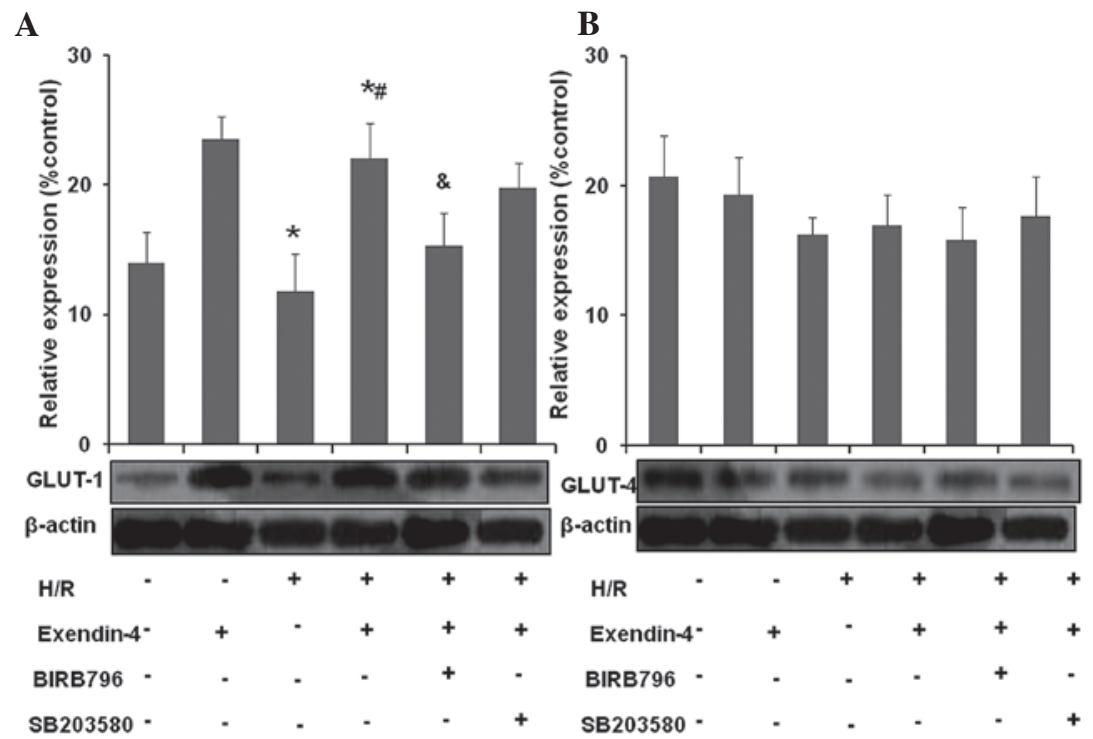

Figure 8. Effects of exendin-4 on (A) GLUT-1 and (B) GLUT-4 translocation in H/R-treated H9c2 cells. H9c2 cells were pre-treated with exendin-4 $(200 \mathrm{nM})$ for $30 \mathrm{~min}$ prior to $\mathrm{H} / \mathrm{R}(12 / 4 \mathrm{~h})$. Two inhibitors of $\mathrm{p} 38$ mitogen-activated protein kinase, BIRB796 $(1 \mu \mathrm{M})$ and SB203580 $(5 \mu \mathrm{M})$, were added to the culture medium and kept for 10 min before the cells were treated with exendine-4. GLUT-1 and GLUT-4 translocation was investigated by measuring the GLUT expression on the cytomembrane following H/R treatment using western blot analysis. Values are expressed as the mean \pm standard deviation $(\mathrm{n}=4) .{ }^{*} \mathrm{P}<0.05$ vs. control group; ${ }^{\#} \mathrm{P}<0.05$ vs. H/R group; ${ }^{\&} \mathrm{P}<0.05$ vs. exendin $-4+\mathrm{HR}$ group. $\mathrm{H} / \mathrm{R}$, hypoxia/reoxygenation; GLUT, glucose transporter.

glucose uptake was significantly decreased in the $\mathrm{H} / \mathrm{R}$ group compared with that in the control group $(\mathrm{P}<0.05)$. As compared with the $\mathrm{H} / \mathrm{R}$ group, pre-treatment with exendin-4 $(200 \mathrm{nM})$ increased the glucose uptake of cells $(\mathrm{P}<0.05)$. These results indicated that exendin-4 enhanced glucose uptake in H/R-injured H9c2 cells.

$H / R$ decreases intracellular expression of p38MAPK $\gamma$ and translocation of GLUT1 in H9c2 cells. To study the role of p38MAPK and GLUT in H/R-induced injury of cardiomyocytes, changes in the protein expression of p38MAPK $\alpha$ and p38MAPK $\gamma$ as well as translocation of GLUT1 and GLUT4 were detected by western blot analysis. Fig. 5A and B shows that the expression of $\mathrm{p} 38 \mathrm{MAPK} \gamma$ in the H/R group was lower than that in the control group $(\mathrm{P}<0.05)$, while no significant changes in $\mathrm{p} 38 \mathrm{MAPK} \alpha$ levels were found $(\mathrm{P}>0.05)$.

With regard to the effects of $\mathrm{H} / \mathrm{R}$ on GLUT, it was demonstrated that $\mathrm{H} / \mathrm{R}$ reduced GLUT-1 translocation from the cytoplasm to the membrane as compared with that in the control group $(\mathrm{P}<0.05)$, while the translocation of GLUT-4 was not significantly decreased $(\mathrm{P}>0.05)$ (Fig. $5 \mathrm{C}$ and $\mathrm{D})$. The results indicated that $\mathrm{p} 38 \mathrm{MAPK} \gamma$ and GLUT-1 may have an important protective role in H/R-injured cardiomyocytes.

Exendin-4 increases the expression of p38MAPK $\gamma$ in $H 9 c 2$-cells subjected to $H / R$. To determine the effects of exendin-4 on p38MAPK $\gamma$ in H/R-injured cardiomyocytes, the $\mathrm{p} 38 \mathrm{MAPK} \gamma$ expression in $\mathrm{H} 9 \mathrm{c} 2$ cells was assessed using western blot analysis (Fig. 6). p38MAPK $\gamma$ expression was significantly reduced in the $\mathrm{H} / \mathrm{R}$ group compared with that in the control group $(\mathrm{P}<0.05)$, while it was markedly enhanced following pre-treatment with $200 \mathrm{nM}$ exendin-4 $(\mathrm{P}<0.05)$. To further study the role of p38MAPK $\gamma$ in the effects of exendin-4 on p38MAPK in H/R-injured cardiomyocytes, two different p38MAPK inhibitors, BIRB796 and SB203580, were used.
As shown in Fig. 6, the effects of exendin-4 on p38MAPK $\gamma$ were inhibited by BIRB796 $(\mathrm{P}<0.05)$, while SB203580 did not show any such effect $(\mathrm{P}>0.05)$. These results suggested that $\mathrm{p} 38 \mathrm{MAPK} \gamma$ may have an important role in exendin-4 mediated protection of cardiomyocytes against H/R injury.

p38MAPK inhibitor BIRB796 abolishes the effect of exendin-4 on glucose uptake in H9c2 cells. To further confirm the role of $\mathrm{p} 38 \mathrm{MAPK} \gamma$ in the effect of exendin-4 on cardiomyocytes, the effect of the p38MAPK inhibitors BIRB796 and SB203580 on the glucose uptake in H9c2 cells was assessed. As shown in Fig. 7, the effects of exendin-4 on the glucose uptake were inhibited by BIRB796 $(\mathrm{P}<0.05)$, while SB203580 did not show any such inhibitory function $(\mathrm{P}>0.05)$. These results suggested that $\mathrm{p} 38 \mathrm{MAPK} \gamma$ may have an important role in exendin-4-mediated glucose uptake.

Exendin-4 increases the translocation of GLUT-1 in $H 9 c 2$ cells subjected to H/R. H/R reduced GLUT-1 translocation from the cytoplasm to the membrane as compared with that in the control group (Fig. $8 \mathrm{~A}$ and $\mathrm{B} ; \mathrm{P}<0.05$ ), while the translocation of GLUT-4 was not significantly decreased (P>0.05). Pre-treatment with $200 \mathrm{nM}$ exendin-4 increased GLUT-1 translocation from the cytoplasm to the membrane $(\mathrm{P}<0.05)$ in comparison to that in the $\mathrm{H} / \mathrm{R}$ group, while the translocation of GLUT-4 was not significantly decreased $(\mathrm{P}>0.05)$. These results indicated that exendin- 4 increased the translocation of GLUT-1 but not GLUT-4 in H/R-injured cardiomyocytes.

By contrast, translocation of GLUT-1 in the presence of exendin-4 was not significantly affected by SB203580 following $\mathrm{H} / \mathrm{R}$ ( $\mathrm{P}>0.05)$, while GLUT-1 translocation was abolished by BIRB796 compared with that in the exendin-4 + H/R group $(\mathrm{P}<0.05)$. No significant effect of SB203580 or BIRB796 on GLUT-4 translocation was identi- 


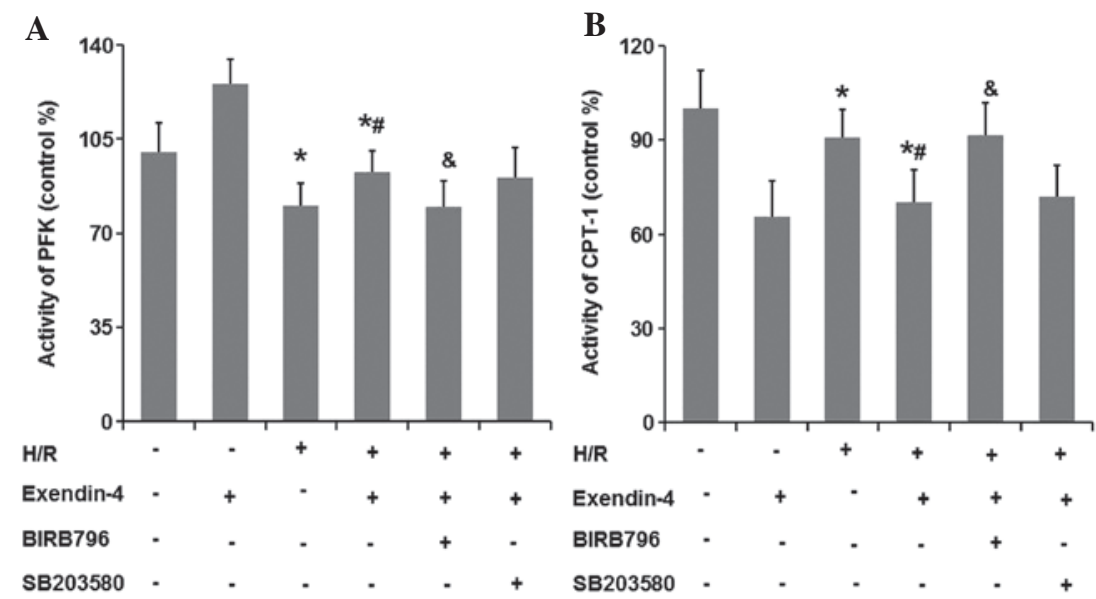

Figure 9. Effects of exendin-4 on the activity of (A) PFK-1 and (B) CPT-1 in H/R-treated H9c2 cells. H9c2 cells were pre-treated with exendin-4 (200 nM) for 30 min prior to $\mathrm{H} / \mathrm{R}(12 / 4 \mathrm{~h})$. Two inhibitors of p38 mitogen activated protein kinase, BIRB796 $(1 \mu \mathrm{M})$ and SB203580 $(5 \mu \mathrm{M})$, were added to the culture medium and incubated for 10 min prior to treatment of the cells with exendine-4. The activity of PFK-1 and CPT-1 was measured by colorimetry. Values are expressed as the percentage of the control and represented as the mean \pm standard deviation $(\mathrm{n}=6)$. ${ }^{*} \mathrm{P}<0.05$ vs. control group; ${ }^{\text {\# }} \mathrm{P}<0.05$ vs. $\mathrm{H} / \mathrm{R}$ group; ${ }^{\text { }} \mathrm{P}<0.05$ vs. exendin-4 + HR group. H/R, hypoxia/reoxygenation; PFK-1, phosphofructokinase-1; CPT-1, carnitine palmitoyltransferase-1.

fied $(\mathrm{P}>0.05)$. These results suggested that $\mathrm{p} 38 \mathrm{MAPK} \gamma$ may have an important role in exendin-4-mediated GLUT-1 translocation in $\mathrm{H} 9 \mathrm{c} 2$ cells subjected to $\mathrm{H} / \mathrm{R}$.

\section{Exendin-4 enhances the activity of PFK-1 and attenuates} that of CPT-1 in H/R-damaged H9c2 cells. To investigate the effects of exendin- 4 on the metabolic balance between glucose oxygen and fatty acid oxidation, the activity of PFK-1 and CPT-1 was examined. As shown in Fig. 9A and $\mathrm{B}$, the activity of PFK-1, the key regulator of glycolysis, was significantly decreased in the $\mathrm{H} / \mathrm{R}$ group compared with that in the control group $(\mathrm{P}<0.05)$. Furthermore, the activity of the rate-limiting enzyme of fatty acid oxidation, CPT-1, was significantly increased in the H/R group compared with that in the control group $(\mathrm{P}<0.05)$. Pre-treatment with $200 \mathrm{nM}$ exendin- 4 increased the activity of PFK- 1 and decreased that of CPT-1 in comparison to that in the $\mathrm{H} / \mathrm{R}$ group $(\mathrm{P}<0.05)$, which suggested that exendin-4 enhanced glycolysis in H9c2 cells subjected to H/R.

The effects of exendin- 4 on the activities of PKF-1 and CPT- 1 were not significantly affected by SB203580 $(\mathrm{P}>0.05)$; however, they were abolished by the use of BIRB796 $(\mathrm{P}<0.05)$. These results suggested that p38MAPK $\gamma$ may have an important role in exendin-4-mediated glycolysis in $\mathrm{H} 9 \mathrm{c} 2$ cells subjected to $\mathrm{H} / \mathrm{R}$.

Exendin-4 increases ATP production in H/R-damaged $H 9 c 2$ cells. As shown in Fig. 10, the levels of ATP were significantly decreased in the H/R group compared with those in the control group $(\mathrm{P}<0.05)$, while the levels of ATP in the exendin- 4 group were significantly increased compared with those in the $\mathrm{H} / \mathrm{R}$ group $(\mathrm{P}<0.05)$. This result suggested that exendin- 4 enhanced the production of ATP in H9c2 cells subjected to H/R. However, BIRB796 treatment significantly inhibited the effect of exendine- 4 on ATP levels in $\mathrm{H} 9 \mathrm{c} 2$ cells following $\mathrm{H} / \mathrm{R}(\mathrm{P}<0.05)$, while SB203580 did not have any significant effect. These results indicated that exendin-4-induced production of ATP in $\mathrm{H} 9 \mathrm{c} 2$ cells subjected to $\mathrm{H} / \mathrm{R}$ may be mediated via $\mathrm{p} 38 \mathrm{MAPK} \gamma$.

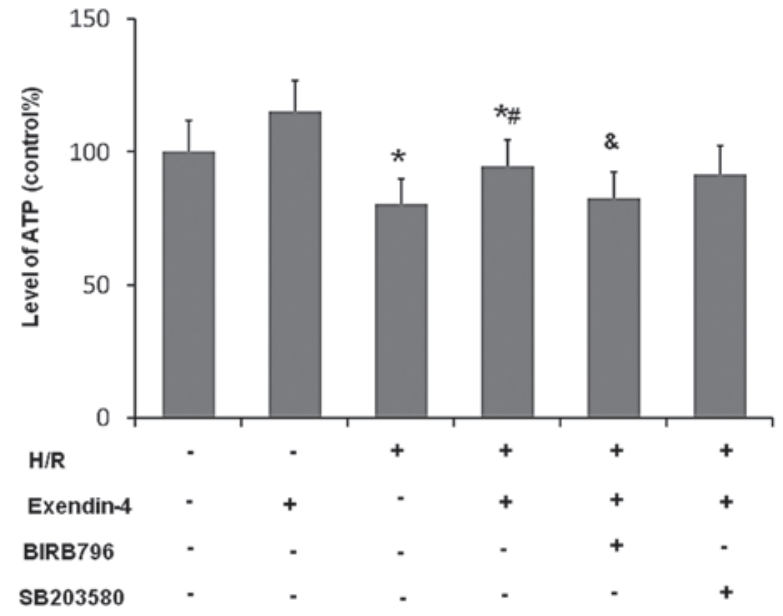

Figure 10. Effects of exendin-4 on the production of ATP in H/R-treated H9c2 cells. H9c2 cells were pre-treated with exendin-4 (200 nM) for $30 \mathrm{~min}$ prior to H/R (12/4 h). Two inhibitors of p38 mitogen-activated protein kinase, $\operatorname{BIRB} 796(1 \mu \mathrm{M})$ and $\mathrm{SB} 203580(5 \mu \mathrm{M})$, were added to the culture medium and cells were incubated for $10 \mathrm{~min}$ prior to treatment with exendine- 4 . The production of ATP was measured using the ATP bioluminescent assay kit. Values are expressed as percentage of control and represented as the mean \pm standard deviation $(\mathrm{n}=6) .{ }^{*} \mathrm{P}<0.05$ vs. control group; ${ }^{*} \mathrm{P}<0.05$ vs. $\mathrm{H} / \mathrm{R}$ group; ${ }^{\circledR} \mathrm{P}<0.05$ vs. exendin- $4+$ HR group. ATP, adenosine triphosphate; H/T, hypoxia/reoxygenation.

\section{Discussion}

The main finding of the present study was that the GLP-1 analogue exendin- 4 reduced H/R-induced cell injury and enhanced glucose uptake as well as glycolysis of cardiomyocytes by activating the p38MAPK signaling pathway in a H9c2 cell model. Importantly, p38MAPK $\gamma$, one subunit of p38MAPK, may have the most significant role in this process.

Effects of GLP-1 and its analogues on ischemic cardiomyocytes in animal experiments or clinic trials have been reported in previous studies, most of which supported its beneficial effects $(10,20,21)$. In line with previous studies, the present study found that exendin-4 reduced H/R-induced cell injury, as 
evidenced by increases in cell viability, decreases in levels of $\mathrm{LDH}$ and CK-MB, and a reduction in cardiomyocyte apoptosis.

Under normal physiological conditions, cardiomyocytes prefer fatty acid as the substrate of metabolism to maintain their function (19). However, the reduced availability of oxygen during low-flow ischemia makes fatty acid oxidation unfavorable, as it aggravates oxygen deficiency due to larger stochiometric amounts of oxygen required for ATP production compared with glycolysis (22), another pathway for ATP production in cardiomyocytes. A study has demonstrated that enhancement of glycolysis through diverse mechanisms or pharmacological interventions was able to delay and prevent ischemic damage (3). Therefore, reducing fatty acid oxidation and shifting the metabolic balance to glycolysis has been a focus in the field of ischemic heart disease treatment (23). In the present study, it was found that exendin-4 optimized the metabolism in H9c2 cells by enhancing glucose uptake, increasing PFK-1 activity and decreasing CPT-1 activity. PFK-1 and CPT-1 are the rate-limiting enzymes in the biological processes of glycolysis and fatty acid $\beta$-oxidation, respectively, and changes in their activity therefore reflect the changes of the two main pathways of energy production $(24,25)$. In addition, the present study found that exendin- 4 treatment significantly increased the levels of ATP in H9c2 cells subjected to H/R. These results strongly indicated that exendin- 4 adjusted the metabolic imbalance in H9c2 cells subjected to $H / R$.

A recent in vivo study reported that exendin-4 failed to increase glucose uptake and glucose oxidation in rat hearts (26); however, the heart metabolism is profoundly different from that of cardiomyocytes in vitro, which may explain why the results contradicted those of the present study. According to previous studies, the effects of GLP-1 and its analogues on glucose uptake were more definite in ischemic cardiac myocytes than those in non-ischemic ones (27). In addition, whether glucose metabolism disorders exist at baseline, may also affect the modification of glucose metabolism by receptor agonists, such as GLP-1 $(21,28)$.

MAPKs are key signal transmitters in animals and humans and p38MAPK is one of their sub-families (29). The p38MAPK signaling pathway has an important role in apoptosis, secretion of cytokines, transcription regulation and resistance to ischemic damage (30-32). The role of p38MAPK in the action of GLP-1 receptor agonists and modification of glucose transportation has been rarely reported, particularly in models of H/R-induced injury, while there are discrepancies between the available studies with regards to the role of p38MAPK and its subunits in the function of GLP-1 and its analogues $(27,33,34)$. Further study of the role of p38MAPK and its subunits in the function of GLP-1 and its analogues is required. In the present study, H/R was found to decrease intracellular expression of p38MAPK $\gamma$ and translocation of GLUT-1 in H9c2 cells. The results indicated that p38MAPK and GLUT may have an important protective role in H/R-injured cardiomyocytes.

It has been reported that the use of BIRB796 could decrease the activity of the four P38MAPK subunits by almost 100\%, while SB203582 failed to exert an obvious effect on the activities of $\gamma$ and $\delta(35,36)$. Furthermore, the amount of p38MAPK $\beta$ and p38MAPK $\delta$ was only $10.6 \%$ and $0.08 \%$ of that of p38MAPK $\alpha$ (37). Previous studies as well as the present study have only focused on the $\alpha$ and $\gamma$ subunits of p38MAPK. The present study found that BIRB796 treatment inhibited the effects of exendin-4, including the enhancement of the glucose uptake, increasing the production of ATP, increasing PFK-1 activity and decreasing CPT- 1 activity, while SB203580 treatment did not exert any inhibitory effects. Considering the fact that the distribution of the $\beta$ and $\delta$ subunit significantly lower than that of the $\alpha$ subunit (only accounting for 10.6 and $0.08 \%$ of that of $\alpha$, respectively, while $\gamma$ is similar to $\alpha$ (37), it is assumed that the function of exendin- 4 in H/R-injured cells is mainly mediated via the $\mathrm{p} 38 \mathrm{MAPK} \gamma$ subunit. These results clearly demonstrated that the p38MAPK signaling pathway, particularly p38MAPK $\gamma$, may have an important role in exendin-4-mediated glycolysis in $\mathrm{H} 9 \mathrm{c} 2$ cells subjected to $\mathrm{H} / \mathrm{R}$. The results of the present study differed from those of Bhashyam et al (34), which indicated that GLP-1 increases myocardial glucose uptake cia p38MAPK in conscious dogs with dilated cardiomyopathy. Zhao et al (27) reported that the total expression of p38MAPK was increased in normal and postischemic isolated rat hearts after treatment with GLP-1; however, information on changes in the levels of p38MAPK subunits were not available. The results of the present study contributed to the knowledge in the field of p38MAPK involvement in the modification of glucose uptake following $\mathrm{H} / \mathrm{R}$; however, as previous studies using various non-uniform models and drugs have produced conflicting results, this mechanism requires further elucidation.

GLUT-1 and GLUT-4 have a critical role in glucose uptake in cardiomyocytes. Enhanced myocardial glucose uptake by upregulation of GLUT-1 and GLUT-4 may be one of the underlying mechanisms to explain the beneficial effect of GLP-1 and its analogues on reducing myocardial injury $(16,38)$. In the present study, in accordance with the identified glucose uptake enhancement in $\mathrm{H} 9 \mathrm{c} 2$ cells subjected to $\mathrm{H} / \mathrm{R}$, if was found that exendin- 4 increased the translocation of GLUT-1 but not that of GLUT-4, which was abolished by BIRB796. These results indicated that exendin- 4 enhanced glucose uptake by upregulation of GLUT-1. The p38MAPK signaling pathway, in particular the p38MAPK $\gamma$ subunit, may have the most important role in this process.

The role of GLUTs in the action of GLP-1 and its analogues has also been reported in several studies, but the results were contradictory among those reports (27,39-41). Arnés et al (41) found that exendin-4 increased the expression of GLUT-4 in rat muscles and that of GLUT-2 in rat livers. However, in this type 2 diabetes mellitus model, an increase of GLUT- 4 was not observed. Another study using a myocardial infarction-induced heart failure model showed that GLP-1 and exenatides analogue AC3174 exerted a cardioprotective function; however, this was not associated with the translocation of GLUT-1 or GLUT-4 (40). Furthermore, Zhao et al (27) reported that GLP-1 increased GLUT-1 and GLUT-4 translocation following ischemic treatment, while Bhashyam et al (34) found that only GLUT-1 translocation was involved in a dog model of dilated cardiomyopathy, which was consistent with the results of the present study. Based on all of these findings, it remains difficult to draw a solid conclusion with regard to the role of GLUTs in the action of GLP-1 and its analogues. However, it can be concluded that the modification of GLUTs by GLP-1 or its analogues is different to that by insulin.

In conclusion, the present study demonstrated for the first time, to the best of our knowledge, that GLP-1 analogue 
exendin-4 improved the energy metabolism of cardiomyocytes by activating the p38MAPK signaling pathway in $\mathrm{H} 9 \mathrm{c} 2$ cells subjected to $\mathrm{H} / \mathrm{R}$ treatment. Importantly, p38MAPK $\gamma$, one subunit of p38MAPK, was indicated to have an important role in this process. Of course, further studies in vivo are required to fully evaluate the cardioprotective effects of exendin-4 and to determine the exact underlying molecular mechanism.

\section{Acknowledgements}

This work was supported by the National Natural Science Fund (grant no. 81100196), the Natural Science Foundation Project of Chongqing Science \& Technology Commission (grant no. CSTC, 2011BB5133), Chongqing Municipal Health Bureau fund (grant nos. 2010-1-07, 2012-2-125 and ZY20132124) and the National Key Clinical Specialties Construction Program of China (grant no. 2011-170). The authors would like to thank Mr. Jianyong Wu and Mr. Dezhang Zhao (Institute of Life Sciences, Chongqing Medical University) for their excellent technical support with the flow cytometric analysis.

\section{References}

1. Hütter JF and Soboll S: Role of fatty acid metabolites in the development of myocardial ischemic damage. Int J Biochem 24: 399-403, 1992.

2. Gambert S, Vergely C, Filomenko R, Moreau D, Bettaieb A, Opie LH and Rochette L: Adverse effects of free fatty acid associated with increased oxidative stress in postischemic isolated rat hearts. Mol Cell Biochem 283: 147-152, 2006.

3. Grynberg A: Effectors of fatty acid oxidation reduction: Promising new anti-ischaemic agents. Curr Pharm Des 11: 489-509, 2005.

4. Avogaro A: Cardioprotective effects of glucagon-like peptide-1: Preclinical and clinical data. G Ital Cardiol (Rome) 12 (Suppl 2): 17-24, 2011 (In Italian).

5. Otto-Buczkowska E: Glucagon and glucagon-like peptides the role in control glucose homeostasis. Part I. Pediatr Endocrinol Diabetes Metab 17: 215-221, 2011 (In Polish).

6. Gallwitz B: Anorexigenic effects of GLP-1 and its analogues. Handb Exp Pharmacol 209: 185-207, 2012.

7. Quintanilla-García $C$ and Zúñiga-Guajardo $S$ : The incretin effect and type 2 diabetes. Rev Med Inst Mex Seguro Soc 48: 509-520, 2010 (In Spanish).

8. Lindamood CA and Taylor JR: Emerging new therapies for the treatment of type 2 diabetes mellitus: Glucagon-like peptide-1 receptor agonists. Clin Ther: Feb 3, 2015 (Epub ahead of print).

9. Harris KB and McCarty DJ: Efficacy and tolerability of glucagon-like peptide-1 receptor agonists in patients with type 2 diabetes mellitus. Ther Adv Endocrinol Metab 6: 3-18, 2015.

10. Bao W, Aravindhan K, Alsaid H, Chendrimada T, Szapacs M, Citerone DR, Harpel MR, Willette RN, Lepore JJ and Jucker BM: Albiglutide, a long lasting glucagon-like peptide-1 analog, protects the rat heart against ischemia/reperfusion injury: Evidence for improving cardiac metabolic efficiency. PLoS One 6: e23570, 2011

11. Bose AK, Mocanu MM, Carr RD, Brand CL and Yellon DM: Glucagon-like peptide 1 can directly protect the heart against ischemia/reperfusion injury. Diabetes 54: 146-151, 2005.

12. Bose AK, Mocanu MM, Carr RD and Yellon DM: Glucagon like peptide-1 is protective against myocardial ischemia/reperfusion injury when given either as a preconditioning mimetic or at reperfusion in an isolated rat heart model. Cardiovasc Drugs Ther 19: 9-11, 2005.

13. Read PA, Khan FZ and Dutka DP: Cardioprotection against ischaemia induced by dobutamine stress using glucagon-like peptide-1 in patients with coronary artery disease. Heart 98: 408-413, 2012 .

14. Read PA, Hoole SP, White PA, Khan FZ, O'Sullivan M, West NE and Dutka DP: A pilot study to assess whether glucagon-like peptide-1 protects the heart from ischemic dysfunction and attenuates stunning after coronary balloon occlusion in humans. Circ Cardiovasc Interv 4: 266-272, 2011.
15. Phong WY, Lin W, Rao SP, Dick T, Alonso S and Pethe K: Characterization of phosphofructokinase activity in Mycobacterium tuberculosis reveals that a functional glycolytic carbon flow is necessary to limit the accumulation of toxic metabolic intermediates under hypoxia. PLoS One 8: e56037, 2013.

16. Idrovo JP, Yang WL, Nicastro J, Coppa GF and Wang P: Stimulation of carnitine palmitoyltransferase 1 improves renal function and attenuates tissue damage after ischemia/reperfusion. J Surg Res 177: 157-164, 2012.

17. Rajaram N, Frees AE, Fontanella AN, Zhong J, Hansen K, Dewhirst MW and Ramanujam N: Delivery rate affects uptake of a fluorescent glucose analog in murine metastatic breast cancer. PLoS One 8: e76524, 2013

18. Lee J and Chang JH: Facile and high-efficient immobilization of histidine-tagged multimeric protein $\mathrm{G}$ on magnetic nanoparticles. Nanoscale Res Lett 9: 664, 2014.

19. Ji L, Zhang X, Liu W, et al: AMPK-regulated and Akt-dependent enhancement of glucose uptake is essential in ischemic preconditioning-alleviated reperfusion injury. PLoS One 8: e69910, 2013.

20. Moberly SP, Berwick ZC, Kohr M, Svendsen M, Mather KJ and Tune JD: Intracoronary glucagon-like peptide 1 preferentially augments glucose uptake in ischemic myocardium independent of changes in coronary flow. Exp Biol Med (Maywood) 237: 334-342, 2012.

21. Gejl M, Søndergaard HM, Stecher C, Bibby BM, Møller N, Bøtker HE, Hansen SB, Gjedde A, Rungby J and Brock B: Exenatide alters myocardial glucose transport and uptake depending on insulin resistance and increases myocardial blood flow in patients with type 2 diabetes. J Clin Endocrinol Metab 97: E1165-E1169, 2012.

22. Tani M and Neely JR: Role of intracellular $\mathrm{Na}^{+}$in $\mathrm{Ca}^{2+}$ overload and depressed recovery of ventricular function of reperfused ischemic rat hearts. Possible involvement of $\mathrm{H}^{+}-\mathrm{Na}^{+}$and $\mathrm{Na}^{+}-\mathrm{Ca}^{2+}$ exchange. Circ Res 65: 1045-1056, 1989.

23. Ferrari R, Pepi P, Ferrari F, et al: Metabolic derangement in ischemic heart disease and its therapeutic control. Am J Cardiol 82: 2K-13K, 1998.

24. Mor I, Cheung EC and Vousden KH: Control of glycolysis through regulation of PFK1: Old friends and recent additions. Cold Spring Harb Symp Quant Biol 76: 211-216, 2011.

25. Aoi W, Naito Y and Yoshikawa T: Potential role of oxidative protein modification in energy metabolism in exercise. Subcell Biochem 77: 175-187, 2014.

26. Nguyen TD, Shingu Y, Amorim PA, Schwarzer M and Doenst T: Glucagon-like peptide-1 reduces contractile function and fails to boost glucose utilization in normal hearts in the presence of fatty acids. Int J Cardiol 168: 4085-4092, 2013.

27. Zhao T, Parikh P, Bhashyam S, Bolukoglu H, Poornima I, Shen YT and Shannon RP: Direct effects of glucagon-like peptide-1 on myocardial contractility and glucose uptake in normal and postischemic isolated rat hearts. J Pharmacol Exp Ther 317: 1106-1113, 2006.

28. Moberly SP, Mather KJ, Berwick ZC, Owen MK, Goodwill AG, Casalini ED, Hutchins GD, Green MA, Ng Y, Considine $\mathrm{RV}$, et al: Impaired cardiometabolic responses to glucagon-like peptide 1 in obesity and type 2 diabetes mellitus. Basic Res Cardiol 108: 365, 2013.

29. Cuenda A and Rousseau S: p38 MAP-kinases pathway regulation, function and role in human diseases. Biochim Biophys Acta 1773: 1358-1375, 2007

30. Erdogdu O, Eriksson L, Xu H, Sjöholm A, Zhang Q and Nyström T: Exendin-4 protects endothelial cells from lipoapoptosis by PKA, PI3K, eNOS, p38 MAPK, and JNK pathways. J Mol Endocrinol 50: 229-241, 2013.

31. Xu H, Li HL, Niu ZY, Li GZ, Cao J and Jiang YD: Involvement of p38 MAPK pathway in GLP-1-induced inhibition of apoptosis in human umbilical vein endothelial cells. Sheng Li Xue Bao 64: 444-448, 2012 (In Chinese).

32. Kawasaki Y, Harashima S, Sasaki M, Mukai E, Nakamura Y, Harada N, Toyoda K, Hamasaki A, Yamane S, Yamada C, et al: Exendin-4 protects pancreatic beta cells from the cytotoxic effect of rapamycin by inhibiting JNK and p38 phosphorylation. Horm Metab Res 42: 311-317, 2010.

33. Ho RC, Alcazar O, Fujii N, Hirshman MF and Goodyear LJ: p38gamma MAPK regulation of glucose transporter expression and glucose uptake in L6 myotubes and mouse skeletal muscle. Am J Physiol Regul Integr Comp Physiol 286: R342-R349, 2004. 
34. Bhashyam S, Fields AV, Patterson B, Testani JM, Chen L, Shen YT and Shannon RP: Glucagon-like peptide-1 increases myocardial glucose uptake via p38alpha MAP kinase-mediated, nitric oxide-dependent mechanisms in conscious dogs with dilated cardiomyopathy. Circ Heart Fail 3: 512-521, 2010.

35. Kuma Y, Sabio G, Bain J, Shpiro N, Márquez R and Cuenda A: BIRB796 inhibits all p38 MAPK isoforms in vitro and in vivo. J Biol Chem 280: 19472-19479, 2005.

36. Caverzasio J and Manen D: Essential role of Wnt3a-mediated activation of mitogen-activated protein kinase p38 for the stimulation of alkaline phosphatase activity and matrix mineralization in C3H10T1/2 mesenchymal cells. Endocrinology 148: 5323-5330, 2007.

37. Dingar D, Merlen C, Grandy S, Gillis MA, Villeneuve LR, Mamarbachi AM, Fiset C and Allen BG: Effect of pressure overload-induced hypertrophy on the expression and localization of p38 MAP kinase isoforms in the mouse heart. Cell Signal 22: 1634-1644, 2010.
38. Huisamen B, Genade S and Lochner A: Signalling pathways activated by glucagon-like peptide-1 (7-36) amide in the rat heart and their role in protection against ischaemia. Cardiovasc $\mathrm{J} \mathrm{Afr}$ 19: 77-83, 2008.

39. Vyas AK, Yang KC, Woo D, Tzekov A, Kovacs A, Jay PY and Hruz PW: Exenatide improves glucose homeostasis and prolongs survival in a murine model of dilated cardiomyopathy. PLoS One 6: e17178, 2011.

40. Liu Q, Anderson C, Broyde A, Polizzi C, Fernandez R, Baron $\mathrm{A}$ and Parkes DG: Glucagon-like peptide-1 and the exenatide analogue AC3174 improve cardiac function, cardiac remodeling, and survival in rats with chronic heart failure. Cardiovasc Diabetol 9: 76, 2010

41. Arnés L, Moreno P, Nuche-Berenguer B, Valverde I and Villanueva-Peñacarrillo ML: Effect of exendin- 4 treatment upon glucose uptake parameters in rat liver and muscle, in normal and type 2 diabetic state. Regul Pept 153: 88-92, 2009. 